\title{
Individual Characteristics Influencing B2B Salesperson Deviance: An Abstract
}

\author{
Mahmoud Darrat, Doug Amyx, and Barry J. Babin
}

\begin{abstract}
The research reported in this presentation describes a psychographic scale intended to assess negatively deviant B2B salesperson behaviors, each one indicating some aspect of salesperson shirking. A deviant salesperson would perform shirking behaviors that are uncharacteristic of peer behavior and that violate established workplace rules, policies, or codes. A study employing a sample of 200 B2B salespeople provides data for scale validation and to examine potential individual difference characteristics that lead to salesperson shirking. A two-step SEM approach provides a test of the proposed measurement theory, using confirmatory factor analysis (CFA) and the subsequent causal model. The CFA model provides reasonably good fit. The shirking scale displays good construct validity with the caveat that the AVE falls below $50 \%$ although the construct reliability estimate is 0.82. Results from the causal model between constructs assess antecedents to shirking. Employees' risk-taking reports relate negatively to shirking, while self-efficacy relates positively. In contrast, no significant relationship between salesperson and organization fit displays an insignificant relationship with shirking. Implications for management and future research are discussed.
\end{abstract}

References Available Upon Request

\footnotetext{
M. Darrat $(\bowtie)$

Auburn University, Montgomery, AL, USA

e-mail:mdarrat@aum.edu

D. Amyx • B.J. Babin

Louisiana Tech University, Ruston, LA, USA

e-mail: damyx@latech.edu; bbabin@latech.edu

(C) Academy of Marketing Science 2017 